\title{
BresDefender: A potential emergency measure to prevent or postpone a dike breach.
}

\author{
D. Janssen ${ }^{1,2, a}$, A.J.M. Schmets ${ }^{2}$, B. Hofland ${ }^{1}$, E. Dado ${ }^{2}$ \& S.N. Jonkman ${ }^{1}$ \\ ${ }^{1}$ Delft University of Technology, Faculty of Civil Engineering and Geosciences, Stevinweg 1, 2628 CN, Delft, The Netherlands \\ ${ }^{2}$ Netherlands Defence Academy, Faculty of Military Sciences, Het Nieuwe Diep 8, 1781 AC, Den Helder, The Netherlands
}

\begin{abstract}
Dikes are designed to withstand a load, with a certain finite probability of occurrence. In case of crises regarding to flood safety, the military is expected to prevent low-laying areas against flooding. Historical attempts show that the effectiveness of emergency measures and strategies are mainly successful caused by the adequate acts of the local people in charge. Based on a literature analysis of breach development, the available time for the application of emergency measures is estimated. This paper introduces the BresDefender strategy, an emergency response strategy, used by the military, to prevent or postpone dike failure. The current BresDefender strategy is a floating pontoon, which can placed on a weakened dike section. It is expected that it can be applied during two scenario's. In the first scenario, the BresDefender is applied during the early stages of breach formation. In the second scenario, it restores the original crest height, where overflow is expected in the near future e.g. in case of macro instability. The BresDefender is expected to stabilize the weakened dike section.
\end{abstract}

\section{Introduction and background}

Historically, the Netherlands has been confronted with challenges related to managing the effects of the variability of water levels in its river system. Nowadays, the protection against water in the Netherlands is based on three levels of a multi-layered safety approach (D'Eliso, 2007; Rijksoverheid, 2009). The first layer in this approach is protection: avoid flooding. The second layer is spatial design: to reduce the effects of flooding. And, the third and last layer is disaster control, e.g. evacuation, to avoid societal disruption. The first safety layer of protection requires a broadly accepted value of the maximal acceptable failure probabilities for water retaining constructions. Currently, these design probabilities are based on assessments of individual, societal and economic risk (Slootjes \& Most, 2016). Note that the maximum accepted risks for flooding are higher than zero. Disaster control within the third layer of safety may involve the deployment of military capacities. Within the Netherlands' context, this complies with the third task of the Dutch army as formulated in the Nederlandse Defensie Doctrine (Sellmeijer, 2019): to offer support during national crises situations such as floods. In these cases the Dutch military is able to support with soldiers and equipment (Reijnen et al., 2018). Two recent cases of high water crises in the Netherlands where the military provided emergency support were the Watersnoodramp in 1953 and the massive evacuation of Rivierenland in 1995.
Until today, an emergency response strategy that can be applied during the first stages of a dike breach, has not been developed. Here, dike breaching is defined as water flowing over the dike, leading to erosion of the core material of the dike. The process of dike breaching can be described and understood from various principal points of view, leading to empirical models, semi-empirical models and process based models (van Damme \& Visser, 2015). These models of breaching, comprising breach initiation and propagation, are an important starting point when aiming at the development of dike breach mitigation strategies. Exploratory research (Albers, 2014; Joore, 2004), has led to several ideas to stop the breaching process in its early phases. The main purpose of this research is to gain insight in the physical processes that govern the either successful, or less successful, application of an emergency response strategy. Focus is on strategies than can be transported to a vulnerable dike section over the water. In this study, firstly a conceptual frame work is developed to relate emergency response strategies with various aspects of dike failure. Secondly, the various aspects that are to be considered within an effective emergency response strategy are discussed: dike stability and breach parameters, dike breach response strategies and finally the specific case of the BresDefender. 


\section{Conceptual framework}

To analyze and classify various emergency response strategies to dike breach events, a conceptual framework has been developed, as summarized in Figure 1. The vertical axis indicates the actual 'state of health' of a dike, and the horizontal axis represents time. Here, the state of health of a dike is defined relatively to the failure probability that the dike was designed for. By this definition, initially the dike is in perfect shape, i.e. fit for its purpose and thus healthy. Over time and without external interventions the structural properties of the dike are expected to deteriorate. Damage will accumulate and grow with time. For this reason the positive direction of the vertical axis in Figure 1 signifies the direction of increasing amount of damage, i.e. lower levels of structural health. One should note that ideally the structural health of a dike remains the same or increases with time. Immediately after construction, curing effects like soil settling will certainly lead to such increase. Also variations over time in moisture content of the dike's soil will lead to associated strength variations of the levee.

However, there are two important reasons why the overall structural state of a dike can be safely assumed to decrease over time, given that no external dike reinforcements have been applied within this time interval:

1. the failure probability will be a function of both, the strength of the dike and the loading intensity. As the loading intensity is believed to increase, e.g. due to the effects of climate change, the overall fitness to purpose, health, will necessarily decrease;

2. by the second law of thermodynamics all open systems will show a long-time trend of the structural health decrease. This is also true for a dike, which is an open system that is loaded over time (interaction) by at least its self-weight and variations in moisture content.

The development of damage over time is presented in Figure 1. The damage of a dike segment at an initial level of damage as indicated is expected to develop over time according to the 'no-intervention' scenario in Figure 1. In the same Figure 1, two threshold levels have been included. If the lowest level, the maximum mitigable damage, is exceeded, no intervention measures can be applied anymore. Measurements or assumptions that provide an estimate of this level, would also give the time available for interventions. If the second level, failure, is exceeded, the dike will not be able to withstand the water anymore. Clearly, the time for a given scenario to develop from the lower to the higher threshold level, is the time available for emergency response measures other than interventions to the dike. Here one could think of evacuation of the land behind the dike, installation of pumps etc. The time required to apply mitigation measures consists of detection, decision making, logistics and placement. Here placement means the actual execution of the dike reinforcement action at the time indicated with 'mitigation' in the figure.

The figure includes four different scenarios. The continuous line, which represents the no intervention scenario, occurs if no action is taken to stop the breaching process. The no-failure scenario represents the perfect intervention, i.e. the breaching process has been completely halted after intervention. The third, extra-time scenario, represents a more realistic intervention scenario: the time to failure of the dike will increase, providing a time benefit that could be sufficient for the dike to survive the specific emergency situation. Finally, the scenario denoted 'unfavorable' in should be avoided at all times. It represents a scenario in which an intervention leads to acceleration of the breaching process.

Altogether we have developed a conceptual framework for the evaluation of emergency response intervention strategies to imminent dike breaches. The next steps will include the introduction of actual dike failure modes as well as possible intervention scenarios. This will be subject of the remaining paragraphs of this paper.

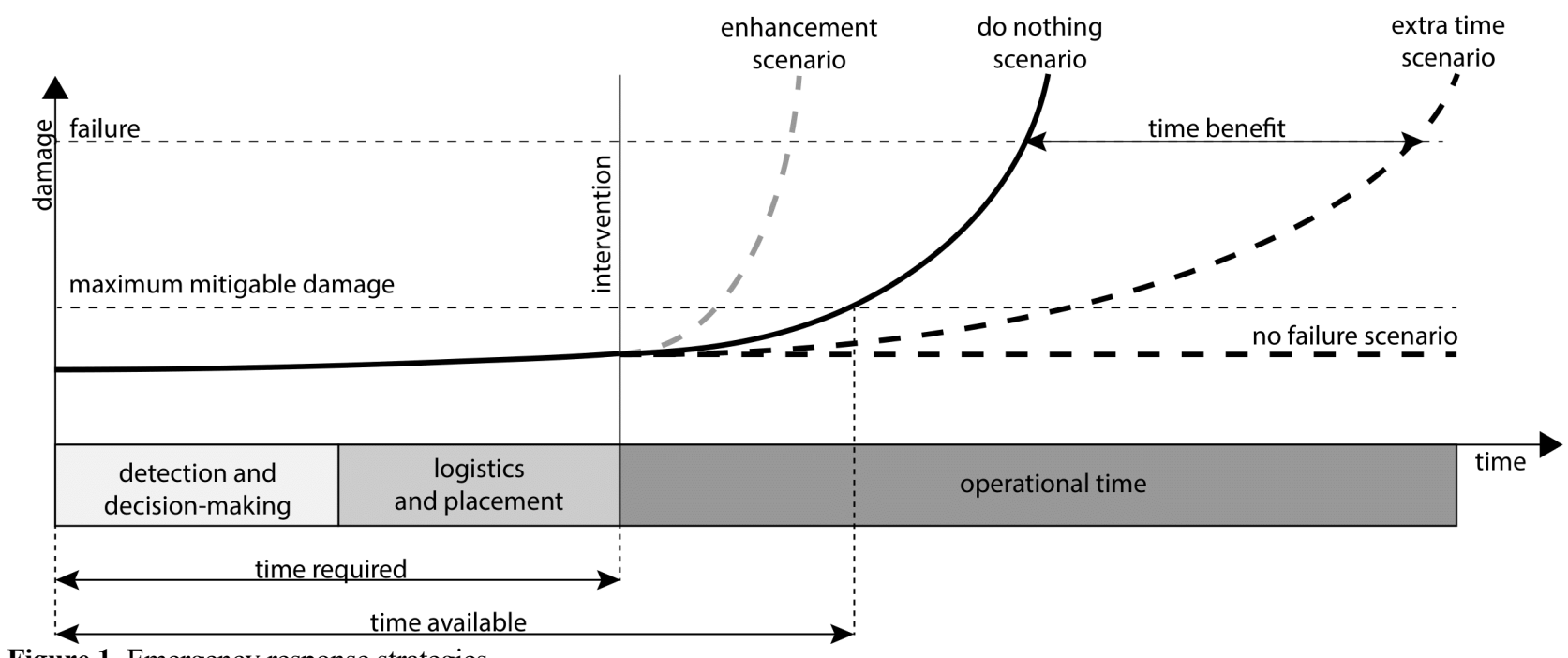

Figure 1. Emergency response strategies 


\section{Dike Robustness}

The main function of a dike is to form a barrier, protecting lower situated areas from flooding. A dike fails if it cannot fulfill this purpose anymore. The failure process of a dike can be distinguished in two phases, breach initiation and formation (Morris, 2013). Breach initiation is the process leading to exposure of the dike core. Breach formation leads to erosion of the core material of a dike, eventually resulting in a dike breach.

Figure 2 shows the most frequently observed failure mechanisms of dikes. Analysis of over one thousand historical dike failure occurrences, have demonstrated that the top 3 main failure mechanisms are external erosion e.g. overflow (61.5\%), internal erosion e.g. piping (16.8\%) and slope failure e.g. macro-instability $(14.2 \%)$ respectively (Özer et al., 2019).
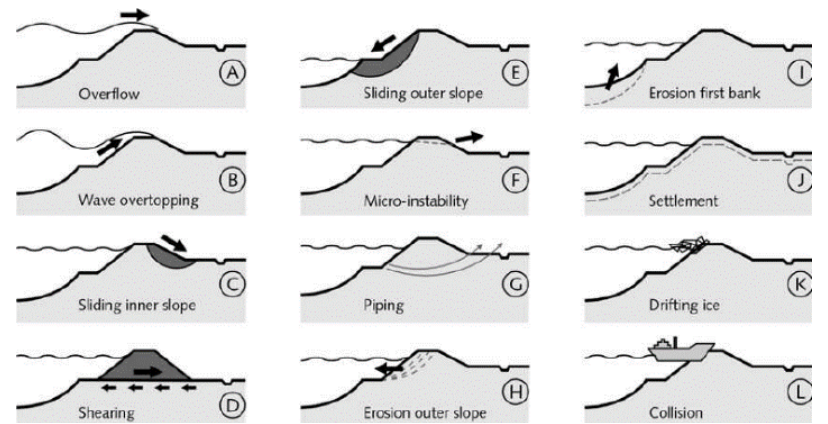

Figure 2. Breach initiation processes (Schiereck, 1998)

\subsection{Top layer erosion}

The material mainly used to prevent the dike core of river dikes from erosion is a top layer of clay covered with grass. The flow velocity of the water across a dike, i.e. the flow velocity component perpendicular to its surface, is a main factor contributing to erosion of the dike body over time. Hewlett et al. (1987) plotted the time to failure to the critical overflow velocity, distinguishing between poor, average and good grass quality. The limiting flow velocities during steady overflow conditions for poor, average and good grass covers lead to grass erosion within one hour are $3.0,3.8$ and $4.5 \mathrm{~m} / \mathrm{s}$ respectively. A time to failure of 50 hours was found for limiting velocities of 1.0, 1.5 and $2.0 \mathrm{~m} / \mathrm{s}$ respectively. D'Eliso (2007) included the effect of weak sections in several levels. In this approach, the removal of grass sections leads to complete disappearance of soil strength. Lang et al. (2016) states, based on results of physical model tests, that the overall contribution of the grass layer to the strength of a dike may be structurally underestimated. After removal of the protective grass clay layer, the breach formation process starts. Thus, the consequences of the observation of a certain level of grass and clay cover damage has to be evaluated in order to formulate the appropriate follow-up action. This 'detection and evaluation step is fitting well into the conceptual framework of Figure 1.

\subsection{Breach formation}

In the previous paragraph the 'birth' of the precursor of a breach, the so-called breach initiation process, was described. Once initiated, the breach will grow, at a speed governed by many parameters, e.g. the overall strength of the dike, the environmental conditions, the actual loading conditions etc. In Figure 1 the 'do-nothing' scenario represents the autonomous breach growth process. Details of the actual breach growth process have to be known in order to come to a justifiable estimate of the damage-time curve of Figure 1.
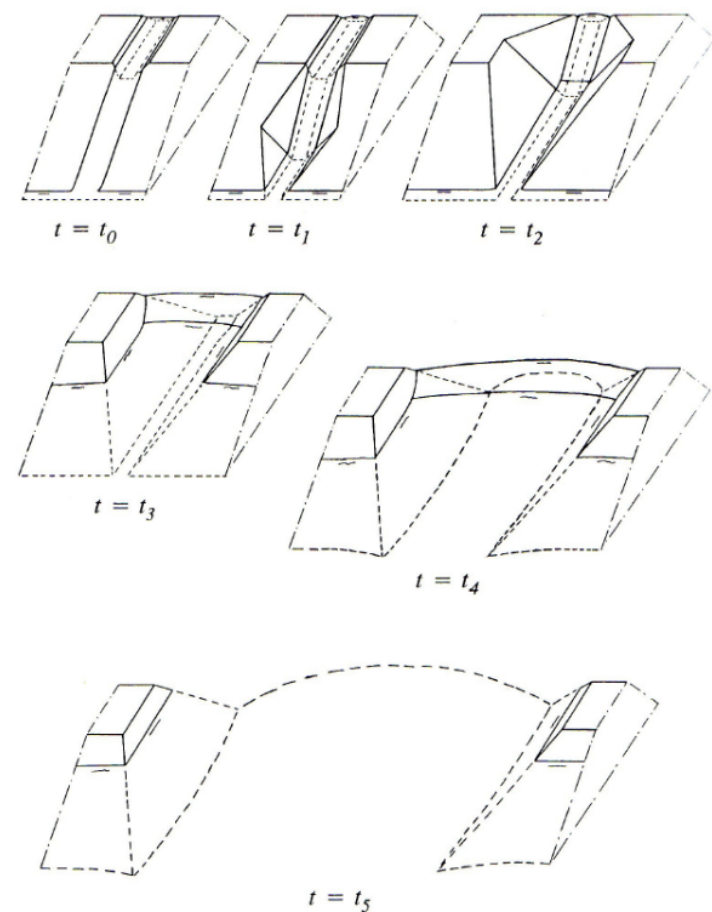

Figure 3. Stages in breach formation (Visser, 1998). Stage I from $t_{0}$ to $t_{1}$. Stage II from $t_{1}$ to $t_{2}$. Stage III from $t_{2}$ to $t_{3}$. Stage IV from $t_{3}$ to $t_{4}$. Stage $V$ from $t_{4}$ to $t_{5}$.

For example, for sand the breach formation process can be divided into five distinct phases, as stated by Visser (1998), as shown in Figure 3. It all begins when water starts overflowing the crest of the dike, which marks the onset of erosion of the landward slope. The process within stage I ( $t_{0}$ to $t_{1}$ ) entails the steepening of the landward slope from its original angle to a certain critical angle, given by the geo-mechanical properties of the soil mass. Thus, stage I ends if this critical angle has been reached. In stage II ( $\mathrm{t}_{1}$ to $t_{2}$ ), the landward slope is eroding towards the riverside slope. Stage II has ended when the entire crest has disappeared over its full width,. In stage III ( $t_{2}$ to $\left.t_{3}\right)$, the crest level decreases. This stage ends if initial crest surface has reached the polder level. During stage IV ( $t_{3}$ to $\left.t_{4}\right)$ the foreland of the dyke comes into play. Here we can distinguish three distinct cases, after (Visser, 1998); (1) an un-erodible foreland, (2) an erodible foreland and (3) no foreland. The presence of a foreland has an effect on the surface erosion rates in this stage and the final breach dimension. Stage $V\left(t_{4}\right.$ to $\left.t_{5}\right)$ starts if the flow through the breach changes from supercritical to subcritical, the Froude number becomes smaller than one. In this phase 
the breach dimensions slowly increase towards an equilibrium width.

Again, the proposed model for the various stages of the breaching process by Visser (1998) is based on dikes that are constructed with non-cohesive sandy materials. The main erosion process of sand is surface erosion. Zhu (2006) found the similar distinguishing phases in the breach development process in clay dikes. The governing erosion process for clay embankments especially during stage I to III is head cut erosion. Headcut erosion is caused by a sudden drop in bed level elevation. Water flowing from high to low elevation leads to an impinging jet flow. Turbulent eddies cause scour holes at the lower parts of the elevation jump, resulting in slope instabilities, leading to erosion. In the case of an embankment with a sandy core and a clay cover, head-cut erosion is expected to be the governing process, caused by the sheltering effect of the top clay layer on the sandy core (D'Eliso, 2007).

\subsection{Breach time}

Little data is available showing the breach width evolution in time, since the collection of data has never been a priority in case of real dike failures. Hence, we combined information on various recorded dike breaches (Figure 4), to have reference datasets with respect to the breach growth process. In Table 1 additional information is provided on the breach processes in Figure 4. The parameter $\mathrm{D}_{50}$ represents the average grain size of the soil sample and c' the cohesion of the soil. Breach initiation is not taken into account, so time equals zero is defined as the moment that core material of the dike starts to erode, corresponding to $t_{0}$ in Figure 3. For the experiments, the breach is initiated by creating a pilot channel, lowering the crest height locally. The breach initiation process of the Breitenhagen case were propagating slip circles, eventually lowering the crest of the dike.

Seed et al. (2006) investigated the dike performances in New Orleans after hurricane Katrina. Based on site visits and through inspections, a correlation between dike robustness and construction details of the dike has been established. Earthen dikes constructed of materials prone to erosion, such as sand, showed more damage than erosion resistant materials, e.g. clay, under comparable circumstances. This is in line with a general trend that can

Table 1. Additional data Figure 4 be observed in Figure 4: erosion is about an order of magnitude (or more) faster in sandy constructions than in clayey constructions. Also, the complete development of the equilibrium breach width in sand dikes is in the order of hours. This is the same time scale as the loading time of the dikes by storms and high tides.

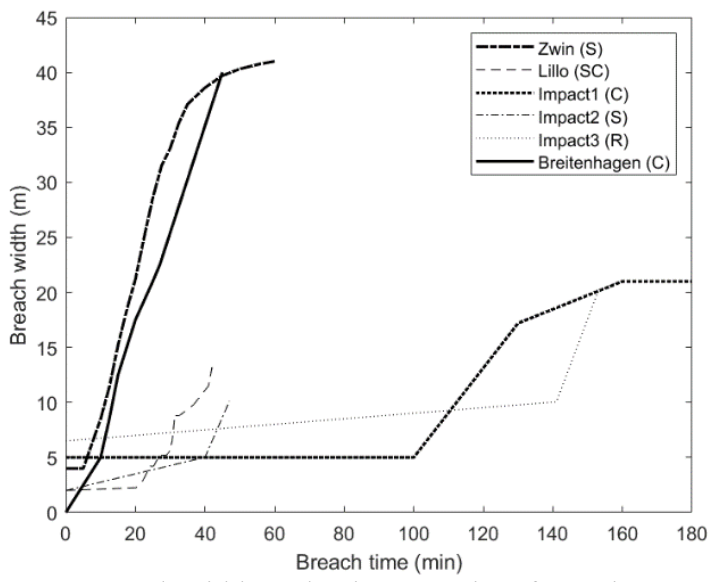

Figure 4. Breach width evaluation over time for various cases from literature. $\mathrm{S}$ is sand, $\mathrm{SC}$ is sandy clay, $\mathrm{C}$ is clay, $\mathrm{R}$ is rock

From the above mentioned tests, it can be inferred that the total time for breach formation is site specific, caused by the heterogeneity of dikes. Large scale experiments show that breaching times are in the order of minutes for sandy dikes and in the order of hours for dikes constructed mainly from cohesive materials.

\section{Emergency response strategies}

Thus far all elements of the conceptual frame work have been detailed except the various intervention scenario's. These emergency response strategies, which are executed to reinforce weakened dike sections, can be classified according to the moment in time of application:

1. Before breach formation. The dike shows signs of initial damages, e.g. cracks, damage to grass cover or (local) settlements. If a maximum load is expected that exceeds the current strength of the dike, emergency measures should be taken.

2. During the breach formation. This phase has been elaborated in the previous paragraph on breach formation. In this case, the type of emergency response intervention may depend on the stage, i.e. stage I to stage IV, of the breach formation process.

\begin{tabular}{|c|c|c|c|c|c|c|}
\hline Name & Type & $\begin{array}{l}\text { Initial } \\
\text { Failure }\end{array}$ & $\begin{array}{l}\text { Dike } \\
\text { material }\end{array}$ & D50 [mm] & $c^{\prime}\left[\mathbf{k N} / \mathbf{m}^{2}\right]$ & Reference \\
\hline Zwin & Experiment & Overflow & Sand & 0.22 & 0 & (Visser et al., 1996) \\
\hline \multirow[t]{2}{*}{ Lillo } & \multirow[t]{2}{*}{ Experiment } & \multirow[t]{2}{*}{ Overflow } & Sandy Clay & 0.135 & 0 & \multirow[t]{2}{*}{ (Peeters et al., 2015) } \\
\hline & & & Clay & 0.04 & 2.0 & \\
\hline Impact1 & Experiment & Overflow & Clay & 0.09 & 4.9 & (Wallingford, 2004) \\
\hline Impact2 & Experiment & Overflow & Sand & 4.65 & 0.9 & (Wallingford, 2004) \\
\hline \multirow[t]{2}{*}{ Impact 3} & \multirow[t]{2}{*}{ Experiment } & \multirow[t]{2}{*}{ Overflow } & Rock & 85 & 0 & \multirow[t]{2}{*}{ (Wallingford, 2004) } \\
\hline & & & Moraine & 7 & 20 & \\
\hline Breitenhagen & Real failure & $\begin{array}{l}\text { Slope } \\
\text { instability }\end{array}$ & Clay & - & 10 & $\begin{array}{l}\text { (Brauneck et al., 2016) } \\
\text { (LHW, 2014) }\end{array}$ \\
\hline
\end{tabular}


3. After the breach formation. Water levels at the river and the low laying areas are equalized, and the catastrophe for the hinterland has already occurred. In this case the focus will shift towards reclaiming the flooded land. This will not be discussed, further

In the remainder of this section we describe several historical intervention attempts to close and strengthen a dike breach, both applied just before or during breach formation.

\subsection{Before breach formation}

For interventions to be applied before the breach formation has started, various options are available. Current guidelines mainly advise to apply sandbags, sand berms or geotextiles depending on the type of damage observed (Foster, 2011; Hofmann et al., 2006). Common emergency response for (expected) overflow is to increase the crest height. Slope instability is avoided by berms and if needed sandbags are used to reestablish the crest height of the dike. Damage to the outer slope can be recovered - or slowed down - by using impermeable geotextiles.

In 2013, a dike near the village of Fishbeck in Germany, showed a crest height reduction of 10 centimeters over a length of approximately 50 meters, which later was attributed to macro-instability (Henning \& Jüpner, 2015). German flood fighters (e.g. military and firefighters) placed sandbags in the berm and on the crest of the dike to avoid further development of the macro-instability and to avoid overflow. Despite many efforts, water started to flow over the sandbags on the crest, leading to complete failure of the dike. While the first damage was observed at 7:00 AM, the dike failed at 0:02 AM the day after.

Another example of intervention before breach formation has started is from Hungary. In 2001, the expected water levels in the Tisza river were higher than the height of the dike crests along the same river (Impact, 2005). Over a length of $30 \mathrm{~km}, 6000$ men increased the crest level several decimeters by sandbags. Leakage through and underneath the sandbags caused saturation of the inner slope, leading to landslides. The landslides evolved towards the crest of the dike which caused breach formation, causing severe flooding of the low laying areas.

\subsection{During breach formation}

During the Watersnoodramp in 1953 a North Sea flood in the Netherlands a vessel sailed into an initial breach near Nieuwerkerk aan den IJssel (Rijkswaterstaat, 1961). Between the first and the second tidal peak, sandbags and sand were used to stabilize the dike, which was sufficient to protectthe dike. It has been claimed that this attempt was mainly successful due to the individual actions of the one person in charge of the dike defense. Moreover, the presence of a revetment at the toe of the dike's outer slope limited the breach dimensions. In Fishbeck vessels were applied to close the breach, however this attempt was only successful after equalization of the water levels (Henning \& Jüpner, 2015).

In the past, helicopters have been deployed to stop the breach formation process. These were used for throwing soil-filled big bags into the breach, for example in Wainfleet in 2019 (Norfolk, 2020) and New Orleans 2005 (Seed et al., 2008). Both breaches were eventually closed after (near) equalization of the water levels had been reached. Chaudhry et al. (2010) reconstructed the breach at the $17^{\text {th }}$ channel street, New Orleans, in a physical model. Sandbags of 13600 and $22680 \mathrm{~kg}$ should have been applied to close the breach, which discharged the water at a flow rate of $898 \mathrm{~m}^{3} / \mathrm{s}$.

To conclude, traditional methods to stop the breach initiation process using sandbags prove to be of limited success due to leakage or failure of individual elements. Historical attempts to stop the breach formation process in its early stages were mainly successful by the adequate response of the person in charge. Attempts to close the breach, after breaching stage III (Figure 3) were generally not successful because of the high flow velocities.

\section{$5 \quad$ BresDefender response strategy}

Finally, a new emergency response strategy is proposed here, BresDefender, literarily translated BreachDefender. This is an emergency response strategy which can be applied to stop or postpone the breaching process of a dike until stage III in the breach formation process. In its current conception the BresDefender intervention strategy is a floating pontoon, normally used by the military to construct temporary floating bridges (Figure 5). A single element has a length of 6.94 meters, a height of 8.13 meters and a weight of 5450 kilograms. The advantage of the pontoon is the possibility to transport the pontoon over water and to place the BresDefender completely from the water. A prototype has been successfully tested during the crisis training exercise Alert 2014. Preliminary research has shown that the BresDefender has an positive effect on the breach formation process (Elsing, 2018). It is expected that the BresDefender is able to locally increase the dike height to block the overflowing water, in case of a local reduced crest height.

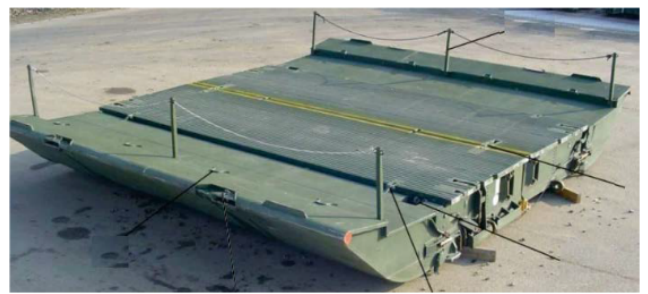

Figure 5. Floating pontoon bridge which is here proposed as BresDefender 


\subsection{Application scenarios}

The reinforcing effect of the BresDefender on a weakened dike will be considered in two scenarios. In scenario 1, the water level is equal to the crest height of the dike. Locally a reduction in crest height will have occurred, causing breach formation (Figure 6). This could be caused by the failure mechanisms of overflow and overtopping. The BresDefender is then applied to stop the water flowing over the dike and to stabilize the breach. One expected difficulty for this scenario is the leakage flowing underneath and around the BresDefender.

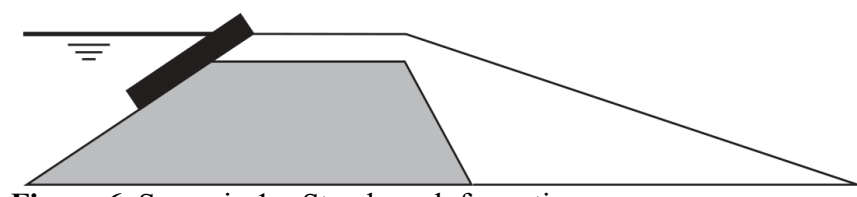

Figure 6. Scenario 1 - Stop breach formation

In scenario 2 (Figure 7), first indications of a dike instability are already spotted, leading to a local reduction of crest height e.g. by the failure mechanism macroinstability. The BresDefender is applied to restore the original crest height and to partly block the water flowing through the dike. In this case the BresDefender stabilises the weakened dike body.

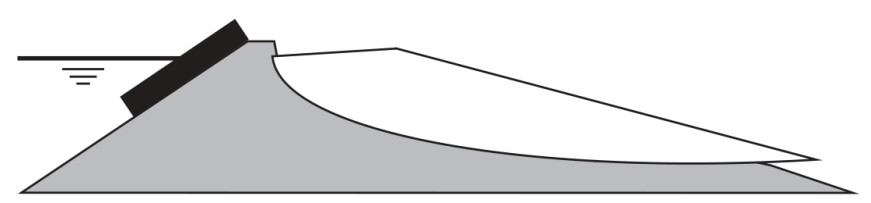

Figure 7. Scenario 2 - Stabilize weakened section

\section{Discussion and future steps}

No scientifically underpinned emergency response strategies to intervene at either the breach initiation nor the breach formation phases are available yet. The main goal of the overall research project is to develop an emergency response strategy that is able to prevent or postpone dike breaching in its early stages. To this goal a conceptual framework has been developed that brings together the various aspects of an emergency response strategy. Firstly, the act of detection and decision making for future interventions, has been identified. Decisions have to be based on scenario's for the effect of intervention, but also on the various processes that contribute to dike breach initiation and formation.

One possible intervention strategy that seems promising has been proposed: the BresDefender. It should first be proven experimentally - at laboratory and real scales - that application of the BresDefender emergency strategy leads to an 'extra time scenario' intervention. The next step is to find the application limits in terms of breach dimensions and leakage assuming successful placement of the pontoon against a dike. The next step is to advise on the optimal placement procedure, resulting in acceptable impulses on the dike heads.
Within the proposed future research effort, three different scales of physical modeling will be applied. The first scale is the laboratory scale. The second scale, the intermediate scale, will include experiments in Floodproof Holland. The third scale, the real-scale will include experiments within the Living Lab Hedwige Prosperpolder.

\section{Acknowledgements}

This project is financially supported by the Faculty of Military Sciences at the Netherlands Defence Academy. The project is also part of the Interreg 2Seas Cooperation Program 'Living Lab Hedwige-Prosperpolder'.

\section{References}

1. Albers, T. S. (2014). Emergency closure of dike breaches - The effect and applicability of emergency measures. (Master thesis). Delft University of Technology, Delft.

2. Chaudhry, M. H., Elkholy, M., \& Riahi-Nezhad, C. (2010). Investigations on levee breach closure procedures. Dep. of Civil and Environmental Engineering: Technical Report, University of South Carolina.

3. D'Eliso, C. (2007). Breaching of sea dikes initiated by wave overtopping. ( $\mathrm{PhD}$ Thesis). University of Braunschweig,

4. Elsing, K. M. (2018). BresDefender: een geïmproviseerde beschermingsmaatregel bij mogelijke dijkdoorbraken - BresDefender: an improvised emergency response strategy for potential dike failures (Bachelor thesis). Nederlandse Defensie Academie, Den Helder.

5. Foster, U. (2011). KPP Meerlaagsveiligheid: Emergency response - Inventarisatie van wereldwijd beschikbare snelle reparatietechnieken en/of noodmaatregelen bij dijkbressen.

6. Henning, B., \& Jüpner, R. (2015). Deichbruch Fischbeck - zwei Jahre danach. Wasser und Abfall, 17(11), 15-19. doi:10.1007/s35152-015-0576-6

7. Hewlett, H. M., Boorman, L. A., \& Bramley, M. E. (1987). Design of reinforced grass waterways (C. I. R. a. I. A. London. Ed. Vol. Report 116). Construction Industry Research and Information Association London.

8. Hofmann, M., Grimmer, M., \& Steuernagel, J. (2006). Instruktion zur Deichverteidigung. Regierungspräsidium Darmstadt, Darmstadt.

9. Impact. (2005). The March 2001 flood on upper Tisza Retrieved from http://www.impact-project.net

10. Joore, I. A. M. (2004). Noodsluiting van een dijkdoorbraak bij hoogwater. (Master thesis). Delft University of Technology, Delft.

11. Lang, M., van Damme, M., Ponsioen, L., Herrero, M., Peeters, P., Klijn, F., \& Samuels, P. (2016). Comparing overflow and wave-overtopping induced breach initiation mechanisms in an embankment 
breach experiment. E3S Web of Conferences, 7. doi:10.1051/e3sconf/20160703004

12. Morris, M. W. (2013). Breaching of earth embankments and dams (PhD thesis). The open university,

13. Norfolk, C. C. (2020). Investigation into the flooding in Wainfleet in June 2019

14. Özer, I. E., van Damme, M., \& Jonkman, S. N. (2019). Towards an International Levee Performance Database (ILPD) and Its Use for Macro-Scale Analysis of Levee Breaches and Failures. Water, 12(1). doi:doi.org/10.3390/w12010119

15. Reijnen, D., Eimers, D., Scholts, N., \& Brouwer, C. A. (2018). Catalogus nationale operaties. Defensiestaf, directie operaties, J34 nationale operaties

16. Rijksoverheid. (2009). Nationaal Waterplan 20092015.

17. Rijkswaterstaat. (1961). Verslag over de stormvloed van 1953.

18. Schiereck, G. (1998). Grondslagen voor waterkeren. report, Rijkswaterstaat, $1998 \mathrm{~b}$. URL repository. tudelft. $\quad$ nl/view/hydro/uuid\% 3 A3bcbbc42-bla44796-80ef-90dd3acf1198.

19. Seed, R. B., Bea, R. G., Abdelmalak, R. I., Athanasopoulos, A. G., Boutwell Jr, G. P., Bray, J. D., . . . Cohen-Waeber, J. (2006). Investigation of the Performance of the New Orleans Flood Protection System in Hurricane Katrina on August 29, 2005: Volume 2. Independent Levee Investigation Team: Final Report, 2.

20. Seed, R. B., Bea, R. G., Athanasopoulos-Zekkos, A., Boutwell, G. P., Bray, J. D., Cheung, C., .. . Wartman, J. (2008). New Orleans and Hurricane Katrina. III: The 17th Street Drainage Canal. Journal of Geotechnical and Geoenvironmental Engineering, 134(5), 740-761. doi:10.1061/(asce)10900241(2008)134:5(740)

21. Sellmeijer, C. J. (2019). Nederlandse Defensie Doctrine.

22. Slootjes, N., \& Most, H. v. d. (2016). Achtergronden bij de normering van de primaire waterkeringen in Nederland. Ministerie van Infrastructuur en Milieu, DG Ruimte en Water, Directie Algemeen Waterbeleid en Veiligheid

23. van Damme, M., \& Visser, P. J. (2015). A SWOT analysis of hydrodynamic models with respect to simulating breaching. Paper presented at the 36th IAHR world congress.

24. Visser, P. J. (1998). Breach growth in sand-dikes. (PhD thesis). Delft University of Technology, Netherlands,

25. Zhu, Y. (2006). Breach growth in clay-dikes. (PhD thesis). Delft University of Technology, 